\title{
Rice, research and real life in the field
}

\section{In the spirit of science, we should ask why studies don't reflect farmers' experiences.}

Sir - I read the News Feature "Feast or famine?” (Nature 428, 360-361; 2004) with great interest, because I have been responsible for introducing the System of Rice Intensification (SRI) in the Indian state of Andhra Pradesh since the summer season of 2003. The experiences of farmers are quite different from what is reported by sceptical scientists.

SRI results are not "a miracle"; they are quite explainable. Planting young seedlings carefully and at wider spacing gives the plant more time and space for tillering and root growth. Careful water management, keeping the field wet and not flooded, gives better yield because it supports healthy root growth. This practice should be encouraged everywhere, as the whole world is facing water shortages. Weeding rice fields with a rotary weeder helps by churning the soil and incorporating the weed biomass as it aerates the root zone. This encourages microorganisms to proliferate and promotes healthy soil. All these practices are known to agronomists - there is nothing new or magic about them.

The costs of SRI are low and its potential productivity is very high, which is more important than ever now that the Green Revolution technologies are showing signs of fatigue.

Even when the Andhra Pradesh farmers were unable to implement all aspects of SRI the first season, just planting young seedlings carefully at wider spacing with somewhat better water management resulted in yield increases of more than 2 tonnes per hectare compared with conventional methods using higher inputs. In 167 on-farm trials, the average yield obtained using SRI practices was
8.1 tonnes per hectare, compared with 5.67 using conventional practices. Average productivity in Andhra Pradesh is 3.89 tonnes per hectare. With more experience, still higher yields may be possible.

Rice yields all over the world have levelled out under the present system of flooded cultivation. We need to be looking for alternatives to existing practices, with an open mind. SRI is still evolving and I hope that the scientific community will collaborate in refining the technology and working out the scientific reasons for the reported higher productivity. This would be more constructive and more in the spirit of science than dismissing SRI with limited data and preconceptions, when the experiences of farmers are so positive.

\section{A. Satyanarayana}

ANGR Agricultural University, Rajendranagar, Hyderabad 500 030, Andhra Pradesh, India

\section{Rice: location is vital in crop management}

Sir - Your News Feature about rice cultivation, "Feast or famine?" (Nature 428, 360-361; 2004), is a classic example of how the debate on a potentially interesting technique can be blurred by its opponents and proponents. In this case, proponents of the System of Rice Intensification (SRI) are reported to claim miracle yields of 15 tonnes or more per hectare, which opponents dispute. However, both decline to consider the location-specific conditions under which, for example, low yields in Madagascar (2 tonnes per hectare) were doubled or even tripled using SRI; these are not miracle yields but still considerable for poor farmers in marginal areas.

There is evidence that such an increase is closely related to better water management, for example non-flooded conditions during the vegetative growth phase of rice in Madagascar's highly reducing soils (J. F. Vizier et al. Agron. Trop. 45, 171-177; 1990). Iron toxicity is probably responsible for depressed yields under permanently flooded conditions in these soils. This could be a starting point in the better understanding of SRI. A closer look at the world's rice-growing areas could also reveal similar acidic soils that would potentially benefit from improved water management.

Even a moderate increase in rice yields (2-4 tonnes per hectare) as a consequence of reduced flooding cannot be maintained unless other crop-management practices are changed as well. For example, nutrient inputs would need to be adjusted to account for the removal of more crop nutrients with the harvest, and weed control will require more attention under non-flooded conditions.

Other factors, such as decreasing farm labour in many rural areas and increasing water scarcity, pose important challenges to rice ecosystems. Only when the entire crop management is geared towards these often location-specific conditions, may new management practices — SRI could be one of many - contribute to the United Nations' goal of reducing hunger and poverty by half in a sustainable way. Huib Hengsdijk, Prem Bindraban Plant Research International, PO Box 16, 6700 AA Wageningen, The Netherlands

\section{Opening the chamber of peer-review secrets}

Sir - I follow with interest the ongoing correspondence about peer review (Nature 427, 196 \& 428, 255; 2004) and agree with the importance of giving recognition to quality reviewers. One option that has not had much attention is making the peer-review process public, so that the whole scientific community can benefit.

For example, Neurosurgery will print a short comment by reviewers highlighting why they felt that the paper deserved publication and what makes it new. One way to extend this idea would be to make each review, and the authors' responses to the reviews for every article, available to all readers. This documentation could be posted as supplementary material on the Internet. Reviewers would have the option of remaining anonymous if they wish.

The educational nature of this information would be invaluable for many reasons. To cite a few: young researchers could learn how to publish outstanding papers and address criticisms; readers could be made aware of the limitations of certain approaches; and we would have a historical record of how peer review improves research findings.

Another practice, which I have found quite useful when reviewing for Neoplasia, is online dialogue between reviewers and authors. Reviewers' comments are posted anonymously online and authors can respond and clarify. The reviewer can help authors improve their studies by explaining why certain experiments were weak. The authors can clarify to the reviewer some aspects that may have been misunderstood in the review, possibly influencing the editorial decision.

This dialogue is unlimited and not mediated by an editor. At the moment it happens in a restricted area of the website, but it could be posted online with the accepted article. Once again, it would be the reviewer's decision whether or not to reveal their identity and assume responsibility for their review.

Erwin G. Van Meir

Departments of Neurosurgery, Hematology and Oncology and Winship Cancer Institute, Emory University School of Medicine, 1365C Clifton Road, Atlanta, Georgia 30322, USA 